\title{
Internet Addiction, Shyness, and Self-Esteem of Pakistani Youth
}

* Dr. Ibtasam Thakur, Assistant Professor

** Dr. Asma Azeem, Assistant Professor (Corresponding Author)

*** Dr. Nadia Gilani, Assistant Professor

\begin{abstract}
Internet addiction is the most rising tool of the present era. Undoubtedly, it has left a strong influence on the minds of youth. Like other parts of the world use of the internet is quite common in Pakistan. The present study aimed to investigate the relationship between internet addiction, shyness, and selfesteem of Pakistani youth. 120 young students; male $(n=60)$ females $(n=60)$ were selected through purposive sampling. The researchers explored how excessive use of the internet brings problems and how all these problems reflect in their behavior. It highlighted how at this point, emerges the significance of self-esteem and shyness. Internet Addiction Test (IAT) developed by Dr. Kimberly Young (1998), the collective self-esteem scale (CSES) developed by Riia Luhtanen and Jennifer Crooker, 1992 and 1994, and Shyness scale developed by Cheek \& Melichor (1985) were used in the present study to measure internet addiction self-esteem and shyness of Pakistani youth. The results of the study indicated that all study variables have a significant positive correlation with each other. It is found that female students have significantly higher scores on shyness as compared to male students and students of private institutes have significantly higher scores on internet addiction than students of public institutes. One of the reasons may be that students of private institutes have more easy access to the internet as compared to public students. The present study indicated that master's level students have significantly higher scores on private collective self-esteem and shyness as compared to bachelor's students.
\end{abstract}

Keywords: Internet Addiction, Self-Esteem, Shyness, Pakistani Youth

Introduction

The use of the Internet is quite common among youth because it provides knowledge and opportunity both; however, its excessive use leads to some negative consequences. The present research aims to explicate the internet addiction and its relationship with the shyness and self-esteem of Pakistani youth. The study explains the impact of internet addiction on youth within the age group ranging from 18 to 26. Excessive use of the internet can adversely affect their social life. There were a smaller number of studies conducted in Pakistan regarding internet addiction and its dreadful consequences. To measure all these consequences which impact the behavior of internet users due to its excessive use is very important to explore. As the internet is excessively used by youth, it has become an integral part of their lives. They perceive it according to their predilection and temperament. It becomes hazardous for a person when its usage becomes an addiction. This obsession is called internet addiction. One category of addiction deals with chemical addiction, drug abuse, etc. and the other is a process addiction, and it is generally non-chemical addiction. Internet addiction may come in the category of process addiction.

\footnotetext{
* Institute of Education, Department of Professional Studies, Lahore College for Women University, Lahore Email: Ibtasam_thakur@hotmail.com

** Department of Special Needs Education, University of Management \& Technology, Lahore Email: asmaa.nouman@umt.edu.pk

***_Department of Teacher Education, Faculty of Education, University of Okara Email: nadia.gilani@uo.edu.pk
} 


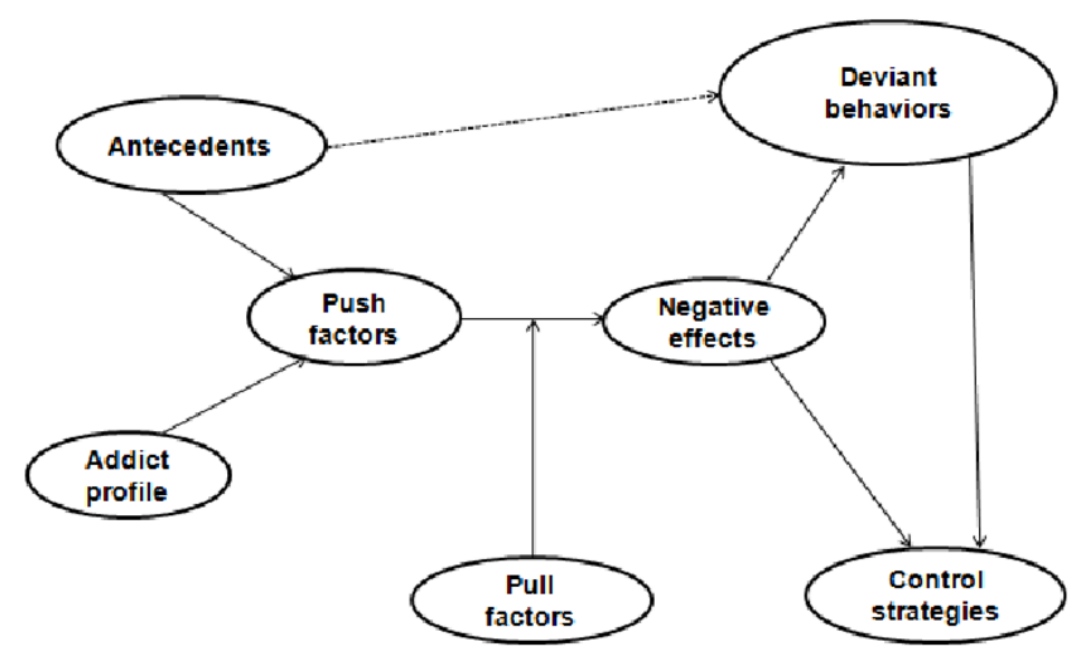

Figure 1.1: Conceptual Model of internet addiction. "Douglas, Mills, Niang, Stepchenkova, Byun \& Ruffini et. al. (2008) (p.3041)"

\section{Internet Addiction}

The importance of information technology cannot be denied despite its deleterious effects on mental health. It has become a symbol of modernization. Although it provides fruitful services and bridges the gap that develops linkages. But certainly, there must be some limit on internet usage. If a person uses the internet more than 5 hours a day, it can cause serious problems to a person's mental and physical health which can lead to addiction. It gives way to pathological behavior. Increased shyness decreases self-esteem and entails into disturbed family relationships and poor academic record among youth. Internet addiction is the same for both genders (Young etal, 2005).

\section{Internet Addiction among Pakistani Youth}

Internet addiction has become a towering problem in Pakistan. Pakistan has been reckoned among the countries in terms of excessive use of the internet. (Farooqi etal, 2013). Although internet addiction is a considerable source to gain knowledge across the globe, it is noted that people of every age group use the internet, but the most affected internet user age group is the young strata of Pakistani society. Doubtlessly, among many other reasons for internet addiction, the availability of internet on cheap rates is on top of the list. A few years back, the internet was not so common in Pakistan and the reason was its non-availability but now it is available in almost every school, college and university. Internet dependency prevails all over the country. Online audios, videos, chatting are prominent features of the internet. Youngsters create their friendships and relationships through the internet. In this process, they waste plenty of time. Anyone can get internet-addicted easily because of its trouble-free, swift, and inexpensive use (Mustafa, 2011).

There are two types of addictive behavior among youth. The first one is to use the internet to gain pleasure and enjoyment. The second one applies to those who use it to divert their attention from worries of life. In both cases, internet use generates isolation among youth (Shapira, 2003). Along with many other psychological and physical problems, internet addiction causes problems of shyness and self-esteem among youth. It has become a reason to disturb their normal psychological patterns in their future life. So, they are not able to attain their targets and fail to utilize the optimum benefit of their potential to lead a productive life.

\section{Internet Addiction and self Esteem}

Self-esteem is an internal experience and it deals with one's emotional evaluation about him. It is evident from various researches that when a person expresses himself in different dating sites, networking sites, and profiles, he expresses himself differently (Sobell, 2007). They portray themselves according to their self-image. It gives them a kind of satisfaction and sometimes narration of false facts give them pleasure to boost their self-esteem. In this way, they try to get those things which they are unable to find in real life. Furthermore, it can be said that appreciation from others makes them more addicted to internet use and lift their self-esteem. Ellison (2008) noted that adolescents with low self-esteem spend much time on social networking than adolescents with high self-esteem. 
In Pakistan, approximately 70 percent of youth uses the internet and among them 80 percent of youth uses Facebook and an average consumption of time is thirty minutes to two hours each day; time consumed on social networking and internet amplified eighteen percent between 2007 to 2008 and facebook users spent 566-percent of their time on the site (Kittinger, Correia, \& Irons, 2012).

\section{Internet Addiction and Shyness}

Shyness is the fear to meet people owing to the reason of being judged and evaluated wrongly. Shyness gives birth to a withdrawn personality. Shyness prevents people to mix up with others. They feel it problematic to meet people face to face. The root cause of this fear is the anxiety of being rejected by the people. Shyness linked with undue monitoring of behavior takes the shape of hesitation; shy personality avoids interaction with people, and as a result, they undergo many disadvantages as compared to other people (Jones \& Carpenter, 1986).

Studies have investigated the divergent viewpoints about shyness and the internet conflict. The first one is that the internet reduces the opportunity of shy individuals to lead a social life. It creates avoidant behavior among them and they avoid real-life situations and interaction with people. The second viewpoint is that the internet promotes healthy social relationships. It minimizes the level of shyness, makes shy individual powerful and allow them to communicate and lead a balanced life in society (Saunders \& Chester, 2008).

\section{The Rationale of the Study}

Internet addiction is relatively a new research area. Internet addiction is now being converted into disorder day by day. Past researches indicated that it was a serious threat to one's mental and physical health. In Pakistan, internet addiction is growing among youth dramatically and unfortunately, there is no effective remedy for it so far. It is a phenomenon that can disable the young users mentally who can become addicted to gambling or more than one category. Therefore, it becomes utmost important to evaluate as to what happens when an individual already having a problem of shyness connects online without physical presence.

\section{Objectives}

1. To find out internet addiction among youth.

2. To find out shyness in internet-addicted youth.

3. To find out self-esteem in internet-addicted youth

\section{Hypotheses}

H1: Internet addiction would be positively correlated with Self-esteem among youth in Pakistan

H2: Internet addiction would be positively correlated with Shyness among youth in Pakistan.

H3: The level of shyness is higher among female internet addicts as compared to males.

\section{Method}

\section{Sample}

120 males and females were selected as a sample of study. Male $(n=60)$, female $(n=60)$, age 18-26.

The youth sample was selected from different public and private sectors of Lahore. Data was collected using purposive sampling technique.

Table 1: Demographics of Pakistani Youth $(\mathrm{N}=120)$

\begin{tabular}{llll}
\hline Sample Characteristics & & $\mathbf{F}$ & $\mathbf{\%}$ \\
\hline Gender & Male & 60 & $50 \%$ \\
& Female & 60 & $50 \%$ \\
Institute & Public & 2 & $20 \%$ \\
Program & BS / MS & & \\
Months of family income: in PKR / Monthly & $50000-$ Above & 120 & $100 \%$ \\
No of Siblings: & $1 . \quad$ Two & 40 & 33.3 \\
& $2 . \quad$ Three & 40 & 33.3 \\
& $3 . \quad$ Four & 40 & 33.3 \\
\hline
\end{tabular}

\section{Instruments}

In the present study, data were collected using three different questionnaires which were standardized questionnaires and were used after the permission of the authors. Every questionnaire was filled by students individually. The first one was the Internet Addiction Test (IAT). It was used to collect data for internet addiction. The second one was the collective self-esteem (CSES) used to collect data to measure self-esteem. The third one was the Shyness scale; it was used to measure shyness. 


\section{Demographic Questionnaire}

The demographic questionnaire was used to assess patient's basic information such as; gender, age, marital status, religion, education, and educational institutes.

\section{Inclusion and Exclusion Criteria}

Those young students were the part of the study who has been internet users for more than one year because excessive internet use takes some time to convert into internet addiction. The age group was ranging 18 to 26 years so they could well understand every question of the questionnaire.

\section{Research Design}

A descriptive research design was used. This study had explored internet addiction, shyness, and selfesteem of Pakistani youth. Thus, the research design was co-relational.

\section{Results}

Mean standard deviation, alpha reliabilities, range, skewness, and kurtosis were used for all study variables (Table 1). Pearson correlation was used among study variables (Table 2). Mean, standard deviation, and T-values were applied for gender differences in study variables (Table 3 to 5). Multiple regression was used to predict shyness among students (Table 6). The data of 120 college students was analyzed. All were users of the internet. Data was analyzed on the scores of the Internet Addiction Test (IAT). The data was also analyzed on the scores of collective self-esteem (CSE). The data was also analyzed on SPSS.

Table 2: Mean, Standard Deviation, Alpha Reliabilities, Range, Skewness and Kurtosis for All Study Variables $(\mathrm{N}=115)$

\begin{tabular}{lllllllll}
\hline \multirow{2}{*}{ Variables } & & & & & \multicolumn{2}{l}{ Range } & \\
\cline { 1 - 1 } & $\mathrm{N}$ & $\mathrm{M}$ & $\mathrm{SD}$ & $\alpha$ & Potential & Actual & Skewness & kurtosis \\
\hline INA & 115 & 55.27 & 8.89 & .78 & $20-100$ & $35-79$ & .35 & .63 \\
MSE & 115 & 11.23 & 4.27 & .62 & $4-24$ & $5-30$ & 1.47 & 3.30 \\
Private SE & 115 & 11.90 & 3.39 & .69 & $4-24$ & $5-22$ & .62 & .88 \\
Public SE & 115 & 11.57 & 3.69 & .73 & $4-24$ & $5-23$ & .85 & .82 \\
ITI & 115 & 11.44 & 3.60 & .70 & $4-24$ & $5-22$ & .68 & .57 \\
Self-esteem & 115 & 46.15 & 13.24 & .89 & $16-96$ & $20-90$ & 1.03 & 1.85 \\
Shyness & 115 & 22.46 & 4.88 & .72 & $9-45$ & $12-35$ & .27 & -.19 \\
\hline
\end{tabular}

Note. INA $=$ internet addiction, MSE $=$ membership self-esteem, $\mathrm{SE}=$ self-esteem, ITI $=$ important to identity.

Table 1 summarizes means, standard deviation, coefficient alpha, and other descriptive for the scales used in the study. As manifested from the table, all the scales show satisfactory reliabilities ranging from .62 (for membership self-esteem) to .89 (for self-esteem). The value of skewness and kurtosis is less than 1 for all study variables except membership self-esteem and self-esteem which indicates that univariate normality is not problematic.

Table 3: Pearson Correlation among Study Variables $(\mathrm{N}=115)$

\begin{tabular}{lllllllll}
\hline & Variables & 1 & 2 & 3 & 4 & 5 & 6 & 7 \\
\hline 1 & INA & - & $.39^{*}$ & $.37^{*}$ & $.37^{*}$ & $.34^{*}$ & $.42^{*}$ & $.31^{*}$ \\
2 & MSE & & - & $.65^{*}$ & $.76^{*}$ & $.64^{*}$ & $.87^{*}$ & $.39^{*}$ \\
3 & Private SE & & & - & $.67^{*}$ & $.86^{*}$ & $.89^{*}$ & $.26^{*}$ \\
4 & Public SE & & & & - & $.67^{*}$ & $.88^{*}$ & $.31^{*}$ \\
5 & ITI & & & & & - & $.89^{*}$ & $.29^{*}$ \\
6 & Self-esteem & & & & & & - & .36 \\
7 & Shyness & & & & & & & - \\
\hline
\end{tabular}

Note. INA = internet addiction, MSE $=$ membership self-esteem, $\mathrm{SE}=$ self-esteem, ITI $=$ important to identity. $*=\mathrm{p}<.001$

Table 2 describes the relationship between the study variables. As is evident from the table, all study variables have a significant positive correlation with each other.

Table 4: Mean, Standard Deviation and T-Values for Gender Differences in Study Variables (N $=115$ )

\begin{tabular}{|c|c|c|c|c|c|c|c|c|c|}
\hline \multirow{3}{*}{ Variables } & \multicolumn{2}{|c|}{$\begin{array}{l}\text { Males } \\
(\mathrm{n}=43)\end{array}$} & \multicolumn{2}{|c|}{$\begin{array}{l}\text { Females } \\
(\mathrm{n}=72)\end{array}$} & \multirow[b]{2}{*}{$\mathrm{t}(113)$} & \multirow{2}{*}{$\mathrm{p}$} & \multicolumn{2}{|c|}{$95 \%$ CI } & \multirow{3}{*}{ Cohen's d } \\
\hline & $\mathrm{M}$ & SD & M & SD & & & $\mathrm{LL}$ & UL & \\
\hline & 54.6 & 10.67 & 55.67 & 7.69 & -.61 & .53 & -.46 & 2.34 & \\
\hline
\end{tabular}




\begin{tabular}{lllllllll}
\hline & & & & & & & & \\
MSE & 10.88 & 4.64 & 11.44 & 4.04 & -.68 & .49 & -2.19 & 1.07 \\
Private SE & 12.02 & 3.83 & 11.83 & 3.12 & .28 & .77 & -1.11 & 1.49 \\
Public SE & 11.07 & 4.27 & 11.88 & 3.30 & -1.13 & .26 & -2.21 & .60 \\
ITI & 11.14 & 3.99 & 11.63 & 3.36 & -.69 & .48 & -1.86 & .83 \\
Self-esteem & 45.11 & 15.81 & 46.77 & 11.51 & -.65 & .52 & -6.71 & 3.41 \\
Shyness & 20.93 & 4.67 & 23.38 & 4.8 & -2.66 & $.01^{*}$ & -4.26 & -.62 \\
\hline
\end{tabular}

Note. INA $=$ internet addiction, MSE $=$ membership self-esteem, $\mathrm{SE}=$ self-esteem, ITI $=$ important to identity.

$*=\mathrm{p}<.05$

Table 3 summarizes the mean differences of gender on study variables regarding the purpose of research. The table suggests that there are non-significant gender differences in study variables except one variable. The female students have significantly higher scores on shyness as compared to male students.

Table 5: Mean, Standard Deviation and T-Values for Educational Institute on Study Variables (N $=115)$

\begin{tabular}{|c|c|c|c|c|c|c|c|c|c|}
\hline \multirow[b]{2}{*}{ Variables } & \multicolumn{2}{|c|}{$\begin{array}{l}\text { Private } \\
(\mathrm{n}=71)\end{array}$} & \multicolumn{2}{|c|}{$\begin{array}{l}\text { Public } \\
(\mathrm{n}=44)\end{array}$} & \multirow[b]{2}{*}{$\mathrm{t}(113)$} & \multirow[b]{2}{*}{$\mathrm{P}$} & \multicolumn{2}{|c|}{$95 \%$ CI } & \multirow[b]{2}{*}{ Cohen's d } \\
\hline & M & SD & M & SD & & & LL & UL & \\
\hline INA & 56.56 & 6.18 & 53.18 & 11.84 & 2 & $.04 *$ & .04 & 6.71 & \\
\hline MSE & 10.92 & 3.10 & 11.75 & 5.67 & -1.01 & .31 & -2.45 & .78 & \\
\hline Private SE & 12.07 & 2.46 & 11.64 & 4.52 & .66 & .50 & -.85 & 1.72 & \\
\hline Public SE & 11.70 & 3.04 & 11.36 & 4.59 & .47 & .63 & -1.07 & 1.75 & \\
\hline ITI & 11.72 & 2.89 & 11.00 & 4.51 & 1.04 & .30 & -.65 & 2.06 & \\
\hline Self-esteem & 46.40 & 8.92 & 45.75 & 18.29 & .25 & .79 & -4.39 & 5.71 & \\
\hline Shyness & 21.69 & 4.07 & 23.70 & 5.80 & -2.18 & .31 & -3.84 & -.18 & \\
\hline
\end{tabular}

Note. INA $=$ internet addiction, MSE $=$ membership self-esteem, $\mathrm{SE}=$ self-esteem, ITI $=$ important to identity.

$*=p<.05$

Table 4 shows the mean differences of educational institutes on study variables. The table suggests that there are non-significant differences between private and public institutes on study variables except one variable. The table describes the students of private institutes have significantly higher scores on internet addiction than students of public institutes.

Table 6: Mean, Standard Deviation and T-Values for Education on Study Variables $(\mathrm{N}=115)$

\begin{tabular}{|c|c|c|c|c|c|c|c|c|c|}
\hline \multirow[b]{2}{*}{ Variables } & \multicolumn{2}{|c|}{$\begin{array}{l}\mathrm{BA} / \mathrm{BSC} \\
(\mathrm{n}=63)\end{array}$} & \multicolumn{2}{|c|}{$\begin{array}{l}\text { MA/MSC } \\
(\mathrm{n}=52)\end{array}$} & \multirow[b]{2}{*}{$\mathrm{t}(113)$} & \multirow[b]{2}{*}{$\mathrm{P}$} & \multicolumn{2}{|c|}{$95 \% \mathrm{CI}$} & \multirow[b]{2}{*}{ Cohen's d } \\
\hline & M & SD & M & SD & & & LL & UL & \\
\hline INA & 52.29 & 8.41 & 55.25 & 9.53 & .02 & .98 & -3.28 & 3.35 & \\
\hline MSE & 10.56 & 3.48 & 12.06 & 4.97 & -1.89 & .06 & -3.06 & .06 & \\
\hline Private SE & 11.33 & 2.73 & 12.00 & 3.96 & -2.01 & $.04 *$ & -2.50 & -.02 & \\
\hline Public SE & 11.14 & 3.27 & 12.10 & 4.13 & -1.38 & .17 & -2.32 & .41 & \\
\hline ITI & 10.90 & 3.29 & 12.10 & 3.87 & -1.78 & .07 & -2.51 & .13 & \\
\hline Self-esteem & 43.93 & 11.04 & 48.84 & 15.16 & -2.00 & $.04 *$ & -9.76 & -.05 & \\
\hline Shyness & 21.48 & 4.50 & 23.65 & 5.10 & -2.43 & $.01 *$ & -3.95 & -.40 & \\
\hline
\end{tabular}

Note. INA $=$ internet addiction, MSE $=$ membership self-esteem, $\mathrm{SE}=$ self-esteem, ITI $=$ important to identity.

$*=\mathrm{p}<.05$

Table 5 shows the mean differences of education on study variables. The table suggests that there are non-significant differences between students of bachelor's and master's on internet addiction, membership self-esteem, public collective self-esteem, and important to identity. Table 5 describes that the master's level students have significantly higher scores on private collective selfesteem, self-esteem, and shyness as compared to bachelor's level students.

Table 7: Multiple Regression Predicting Shyness among Students (N=115)

\begin{tabular}{lllll}
\hline Variables & $\mathrm{B}$ & SEB & $\mathrm{B}$ & $\Delta \mathrm{R}^{2}$ \\
\hline INA & .10 & .05 & $.19^{*}$ & \\
Shyness & .10 & .03 & $.28^{* *}$ & .15 \\
& & & & \\
\hline
\end{tabular}

Note. INA $=$ internet addiction 
$*=\mathrm{p}<.05, * * \mathrm{p}<.01$

Table 6 explains that internet addiction and shyness is a significant positive predictor of shyness at $\mathrm{F}(2,112)=10.73, \mathrm{p}<.001$ and it explains $15 \%$ variance in this model.

\section{Discussion}

The first hypothesis of the study was disapproved. It may be due to cultural differences or may be due to limitations of the study. Students who were included as the sample were from the age range of 1826 they might have been less vulnerable towards internet addiction. Another study indicated that the level of internet addiction of male students is higher who spent approximately eight hours on the internet which ultimately affects their academic efficiency (Ozlem\& Mehmet, 2008). Internet users spend much time online rather than real interaction with people (Kumar 2004). The third hypothesis of the study was that Internet addiction plays a role to increase shyness among young females, past researches have supported this hypothesis. The Internet offers an alternative for people to gratify their social and emotional needs, which might be unmet in their traditional offline networks. A shy individual may feel more comfortable and relaxed to communicate through the internet as compared to face to face communication which leads him towards internet addiction (Schneider \& Amichai, 2010)

\section{Conclusion}

This study indicated that internet addiction and self-esteem are positively correlated. Findings of the present study yield that all study variables have a significant positive correlation with each other. It is found that female students have significantly higher scores on shyness as compared to male students and students of private institutes have significantly higher scores on internet addiction than students of public institutes. One of the reasons may be that students of private institutes have more easy access to the internet as compared to public students. The present study indicated that master's level students have significantly higher scores on private collective self-esteem, self-esteem, and shyness as compared to bachelor's students.

\section{Limitations and Suggestions}

Similar to other social researches the present study also has some limitations.

There would be low generalizability of the results on the whole population because of the limited population of 120 young students. To increase generalizability, the sample size should be increased in further studies. Further, the study should enhance its scope in different cities of Punjab province. It was laborious for one participant to fill three questionnaires at a time. It may lack concentration and honesty. So, some students might have responded to the questionnaire without understanding its items properly. There are many other gaps in the study; further research studies may include a sample age of more than 26 years and less than 18 years for more generalizability of results. Internet addiction is a highly prevailing issue these days. For further studies, different variables can be targeted which can cause internet addiction or that are results of internet addiction.

The present study may prove helpful for parents to gauge the personality of their child who spends excessive time on the internet. This study provides a platform for addressing the psychological issues related to internet addiction.

\section{References}

Cheek, J.M., \&Melchior, L.A. (1985).Measuring the three components of shyness. Paper presented at the meeting of the American Psychological Association, Los Angeles, CA.

Douglas, A. C., Mills, J. E., Niang, M., Stepchenkova, S., Byun, S., Ruffini, C., Lee, S. K. et al. (2008). Internet addiction: Meta-synthesis of qualitative research for the decade 1996 -2006. Journal of Computer in Human Behavior, 24, 3027-3044. Retrieved January 23, 2011, from Science Direct.

Ellison N. Steinfield C. Lampe C. (2008).The benefits of Facebook"friends": social capital and college students' use of online social network sites. J Comput-Mediat Comm 12:1143-68.

Farooqi, H., Patel, H., Aslam, H. M., Ansari, I. Q., Khan, M., Iqbal, N., \& Asad, N. (2013).Effect of Facebook on the life of Medical University students. International archives of medicine, 6(1), 40.

Jones, W.H., \& Carpenter, B.N. (1986). Shyness, social behavior, and relationships. In: W.H. Jones, J.M.Cheek, \& S.R. Briggs (eds.), Shyness: perspectives on research and treatment. New York: Plenum Press, pp.227-249.

Kittinger, R., Correia, C., \& Irons, J. (2012). Relationship between Facebook use and problematic 
Internet use among college students. Cyberpsychology, Behavior, and Social Networking, 15(6), 324-327.

Kumar, A. (2004). Ency. Of teaching of internet. New Delhi India: Anmol Publications PVT. LTD.

Luhtanen, R., \& Crocker, J. (1992). A collective self-esteem scale: Self-evaluation of one's social identity. Personality and Social Psychology Bulletin, 18, 302-318.

Mustafa KOC, (2011). Internet Addiction and Psychopathology. TOJET: The Turkish Online Journal of Educational Technology. 10, 1.

Ozlem Cakir Balta \& Mehmet Baris Horzum, (2008). Ankara University, Journal of Faculty of Educational Sciences, 41, 1, 187-205.

Schneider, B. H., \& Amichai-Hamburger, Y. (2010). Electronic communication: Escape mechanism or relationship-building tool for shy, withdrawn children and adolescents? The development of shyness and social withdrawal. 236-261. New York: Guilford Press.

Shapira, N., Lessig, M., Goldsmith, T., Szabo, S., Lazoritz, M., Gold, M. (2003) Problematic internet use: proposed classification and diagnostic criteria. Depression and Anxiety, 17,

Saunders, P.L., \& Chester, A. (2008). Shyness and the Internet: social problem or panacea. Computers in Human Behavior, 24, 2649-2658

Sobell, L.C. (2007). The Phenomenon of Self-Change: Overview and Key Issues. Promoting SelfChange From Addictive Behaviors. Springer Science Business, New York.

Young, K. S. (1998) Internet addiction: The emergence of a new clinical disorder. CyberPsychology and Behavior, 1(3), 237-244.

Yang, C. K., Choe, B. M., Baity, M., Lee, J. H., Cho, J. S. (2005).Profiles of senior high school students with excessive internet use. Can J Psychiatry 50, 407-14 